\title{
Aspectos morfológicos de células da série eritrocítica de Caiman crocodilus yacare (Daudin, 1802; Reptilia, crocodilia)
}

Weber Leal de MOURA ${ }^{1}$ Vinicius Antonio Lima de CARVALHO²

Antenor Aguiar SANTOS ${ }^{3}$

Mizue Imoto EGAMI ${ }^{5}$

Maria Regina SILVA ${ }^{6}$

Mihoko YAMAMOTO ${ }^{7}$

\section{Correspondência para:}

WEBER LEAL DE MOURA

Setor de Histologia e Embriologia

Universidade Federal do Piauí

Campus Ministro Petrônio Portela

64.049-550 - Teresina - PI

webermoura@hotmail.com

Recebido para publicação: 06/02/2003 Aprovado para publicação: 13/07/2005

\author{
1 - Departamento de Morfologia da Universidade Federal do Piauí, Teresina - PI \\ 2 - Médico Veterinário \\ 3 - Biólogo, São Paulo-SP \\ 5 - Departamento de Morfologia da Universidade Federal de São Paulo, São Paulo - SP \\ 6 - Departamento de Patologia da Universidade Federal de São Paulo, São Paulo - SP \\ 7 - Departamento de Medicina da Universidade Federal de São Paulo, São Paulo - SP
}

\section{Resumo}

Com o objetivo de estudar o sistema hematopoético do réptil Caiman crocodilus yacare, foram utilizados cinco exemplares hígidos e jovens (aproximadamente um ano de idade), provenientes de São Paulo e de Mato Grosso do Sul. Amostras de sangue periférico foram colhidas em EDTA, através da punção do seio venoso cervical, e da medula óssea por punção aspirativa do osso femural. Estudo histológico da medula óssea femural foi realizado através da coloração por HE, Giemsa e técnica de Gomori para fibras reticulínicas. Os esfregaços de sangue e de medula foram processados para coloração panótica (Leishman ou Rosenfeld). A presença de sítios hematopoéticos ativos foi demonstrada histologicamente nos cortes transversais do fêmur, principalmente no terço distal. As células da linhagem eritrocítica foram encontradas dentro dos vasos capilares sinusóides medulares, na região central do osso. As células precursoras desta linhagem estavam aderidas à parede do vaso, e suas sucessoras distribuídas em direção ao centro do sinusóide à medida que amadureciam. Nos esfregaços de medula, as células imaturas da linhagem eritrocítica mostraram-se arredondadas e com núcleo predominantemente frouxo, em contraposição às células maduras, de núcleo condensado e forma em geral elíptica. Foram vistos pró-eritroblastos, eritroblastos basofílicos, policromáticos e ortocromáticos, e finalmente eritrócitos.

\section{Introdução}

Vários trabalhos descreveram célu-
las sanguíneas maduras de rép-
teis ${ }^{1,2,3,4,5,6,7,7,9,10,11,12,13,14,15}$. Nesses vertebrados
a produção das células sanguíneas ${ }^{16}$ ocorre
predominantemente na medula óssea,
particularmente de ossos longos ${ }^{16,17,18,19,20,21,22,23}$,
mas células não maduras podem ser vistas
no sangue periférico ${ }^{3,24}$. Alguns autores
descreveram as células da série eritrocítica;
embora o eritrócito de réptil seja diferente ${ }^{17}$
do de mamíferos, o processo de produção da célula é semelhante. Ocorre, entretanto, uma baixa seletividade na passagem de células da medula para o sangue circulante, sendo que as células ainda indiferenciadas atingem a corrente sangüínea. Trabalhos mostram que a enzima tetrahidrofolato desidrogenase apresenta atividade variável com o grau de maturidade celular, sendo decrescente na série eritrocítica e crescente na série granulocítica ${ }^{18}$. Outros indicam correlação ${ }^{21}$ entre a hematopoese e a regeneração da cauda; o número de eritrócitos aumenta, havendo também 
incremento da hemoglobina. Certos autores ${ }^{20}$ relataram eritropoese na luz dos vasos, e granulopoese extravascular. Quanto à resposta eritropoética a certos hormônios ${ }^{22}$, alguns provocam variações no hematócrito e na hemoglobina. Trabalhos observaram ${ }^{26}$ que a hematopoese e a linfopoese ocorrem na medula óssea ainda na fase embrionária e que a eritropoese ${ }^{19}$ ocorre na medula óssea a partir do primeiro ano de vida, enquanto outros $^{23}$ observaram a persistência de glóbulos imaturos no sangue circulante de répteis adultos. Outros autores abordaram ainda a eritropoes $\mathrm{e}^{27}$ e a citologi ${ }^{28}$ do sangue periférico de répteis.

Considerando o exposto, propomonos a estudar os aspectos morfológicos de células da série eritrocítica de Caiman crocodilus yacare. Consideramos que podemos contribuir para preencher algumas lacunas observadas na literatura compulsada.

\section{Materiais e Métodos}

\section{Animais}

Utilizou-se cinco exemplares jovens (com tamanho de aproximadamente $50 \mathrm{~cm}$ e idade estimada de 1 ano) de Caiman crocodilus yacare ou jacaré-do-pantanal, dois pertencentes à Fundação Parque Zoológico de São Paulo, um ao Instituto de Aqüicultura da Universidade Estadual Paulista no município de Rio Claro, no Estado de São Paulo, e dois oriundos de criatório particular no município de Terenos, Estado de Mato Grosso do Sul.

\section{Colheita das amostras de medula óssea (aspirado)}

Feita por punção do fêmur no terço distal com a utilização de seringa de $20 \mathrm{ml}$, agulha especial tamanho 30x12, com mandril, fazendo-se imediata transferência para lâmina de vidro (análises morfológicas) e tubo de ensaio. A colheita de sangue periférico realizou-se em EDTA utilizando-se seringa provida de agulha comum, a partir do seio venoso cervical. Parte do volume foi utilizado no preparo de esfregaços em lâminas, para análises morfológicas. Outra parte foi utilizada na contagem total das células sangüíneas.

Método para contagem total de células sangüíneas

Realizada em triplicata para cada amostra, conforme a técnica clássica utilizada para sangue humano.

\section{Realização de biópsia do fêmur}

Depois de colhidas as amostras de sangue e de medula óssea (aspirado), os animais foram submetidos à anestesia geral por inalação de éter sulfúrico e o fêmur foi retirado cirurgicamente. Imediatamente o osso foi raspado para melhor penetração do fixador (formol a 10\% em tampão fosfato

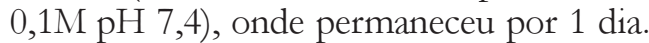
Procedeu-se à descalcificação. Os blocos foram cortados em micrótomo rotativo, $\operatorname{com} 2 \mu \mathrm{m}$ de espessura. As colorações foram feitas pelos métodos da Hematoxilina e Eosina, de Giemsa e de Gomori para fibras reticulínicas.

\section{Coloração para análise morfológica dos esfregaços de medula óssea e de sangue periférico \\ Fêz-se pelos métodos de Leishman e de Rosenfeld. As lâminas foram examinadas ao microscópio de luz, utilizando-se ocular $8 \mathrm{x}$ acoplada a objetiva de imersão de 100x, com aumento final de 800 vezes.}

\section{Documentação fotográfica}

Realizada com sistema fotomicrográfico, acoplado a adaptador para fotos, condensador universal e sistema microscópico.

\section{Resultados e Discussão}

\section{Contagem total de células sangüíneas}

Encontramos células da série vermelha na quantidade média de $7 \times 10^{5} /$ $\mathrm{mm}^{3}$.

\section{Biópsia do fêmur}

Macroscopicamente, após realizar vários cortes transversais no osso, a região distal mostrou-se mais rica em medula óssea vermelha que a proximal, o que determinou 


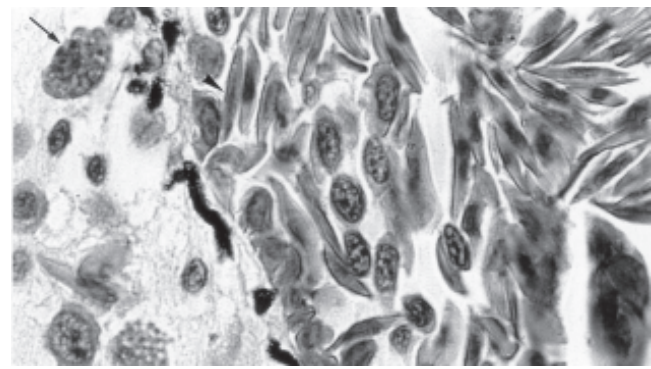

Figura 1 - Fotomicrografia de corte de medula óssea onde se observa no limite entre as regiões subendosteal e vascular central grande quantidade de células do sistema hematopoético Notar células leucocíticas extravascularmente (seta) e eritrocíticas (cabeça de seta) dentro do capilar sinusóide. Método da Hematoxilina e Eosina. Aumento de 1450x

a escolha do local para a realização dos cortes histológicos.

Histologia da medula óssea femural corada com Hematoxilina e Eosina

Em cortes transversais foram observados sítios hematopoéticos ativos nas regiões subendosteal e central do osso, porém com marcantes diferenças quanto ao tipo de célula hematopoética encontrada. Assim, na região central foram vistos muitos vasos capilares sinusóides medulares, repletos de células da linhagem eritrocítica em vários estágios de diferenciação. As células menos diferenciadas mostraram-se aderidas ao endotélio vascular, enquanto aquelas com algum grau de diferenciação apresentaramse deslocadas para a região central e as maduras localizaram-se bem ao centro da luz do vaso (Figuras 1 e 2). Quando os capilares situam-se junto à região subendosteal, é possível observar num mesmo campo células eritrocíticas imaturas localizadas intravascularmente e células imaturas leucocíticas extravascularmente.

\section{Corte histológico de medula óssea femural corada com Giemsa}

$\mathrm{Na}$ porção mais central, predominam sinusóides volumosos, em geral completamente preenchidos por eritrócitos. Estes apresentam aspecto fusiforme e núcleos ovóides. Entre os sinusóides predomina tecido adiposo. Não se observam trabéculas ósseas.

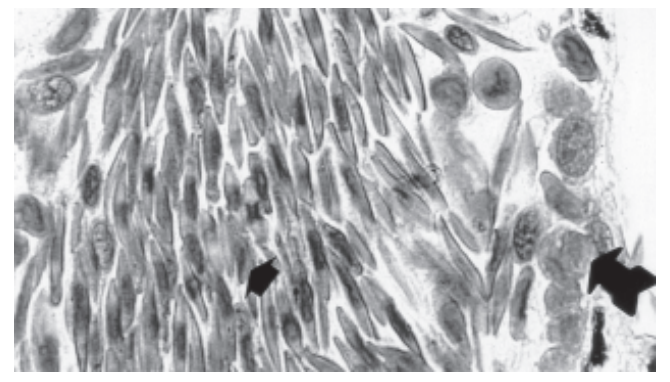

Figura 2 - Fotomicrografia de corte de medula mostrando um sinusóide repleto de células eritrocíticas. Notar que as menos diferenciadas formam fileira aderidas à parede do endotélio (seta), enquanto as mais diferenciadas dirigem-se ao centro da luz do vaso (cabeça de seta). Método da Hematoxilina e Eosina. Aumento de 1450x

Corte histológico de medula óssea femural corado pelo método de Gomori para fibras reticulínicas Após impregnação pela prata observou-se uma trama reticular fina entre os sinusóides que se adensa na região abaixo do osso cortical (Figura 3).

Esfregaços do aspirado de medula óssea femural e sangüíneos corados com Leishman ou Rosenfeld

Observamos células indiferenciadas sem definição de linhagem, de aspecto imaturo, apresentando forma grosseiramente arredondada, com núcleo grande vesiculoso provido de nucléolos evidentes. O citoplasma, pouco volumoso, mostra certa basofilia, mais acentuada em determinadas regiões (Figura 4). Encontramos células da Linhagem eritrocítica em diferentes estágios de maturação, aqui descritas em ordem crescente

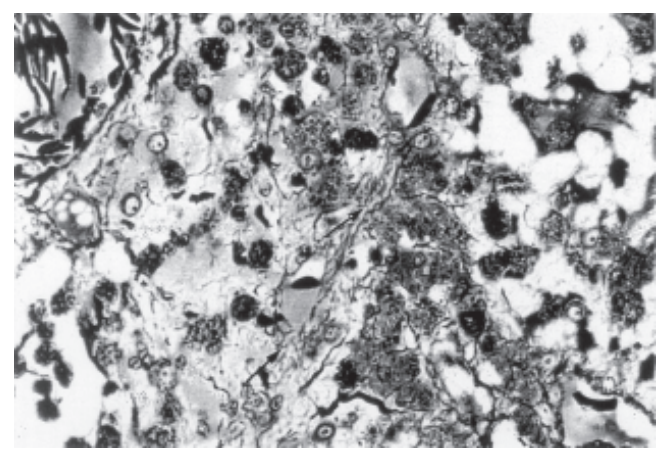

Figura 3-Fotomicrografia de corte de medula evidenciando na região subendosteal grande quantidade de fibras reticulínicas em preto (setas). Método de Gomori para fibras reticulínicas. Aumento de 600x 


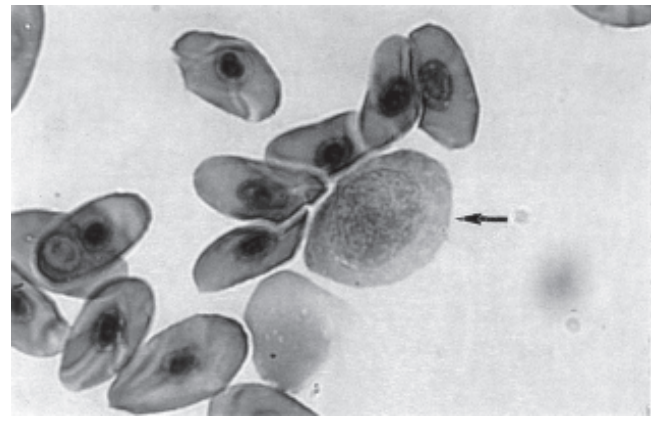

Figura 4 - Fotomicrografia de esfregaço de aspirado de medula óssea apresentando uma célula imatura sem definição de linhagem (seta). Notar o núcleo grande com cromatina frouxa, presença de nucléolos e citoplasma basófilo. Método de Rosenfeld. Aumento de 1450x

de diferenciação. $\mathrm{O}$ eritroblasto basófilo apresenta elevada relação núcleo/citoplasma com cromatina heterogênea em grumos. $\mathrm{O}$ citoplasma apresenta basofilia, mais intensa na periferia (Figura 5). O eritroblasto policromático, menor em comparação com a anteriormente descrita, apresenta núcleo grande com grumos de heterocromatina; pode apresentar vacúolos no citoplasma, ainda basófilo (Figura 6); são encontradas figuras de mitose (Figura 7). O eritroblasto ortocromático apresenta volume maior em relação ao eritrócito maduro, mostrando forma já ovalada, diferente das fases precursoras arredondadas; o citoplasma com alguma acidofilia pode apresentar vacúolos; núcleo grande, com tamanho maior que o observado na célula madura e

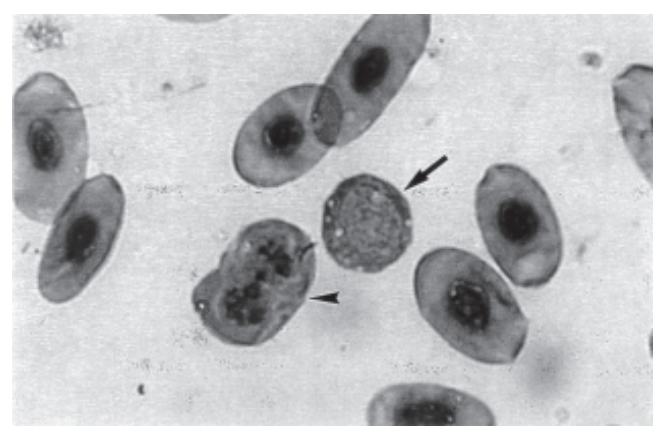

Figura 6 - Fotomicrografia de aspirado de medula mostrando um eritroblasto (seta) policromático. Núcleo com cromatina em grumose presença de vacúolos no citoplasma pouco abundante de tonalidade acinzentada e um eritrócito (cabeça de seta) em mitose. Método de Rosenfeld. Aumento de 1450x

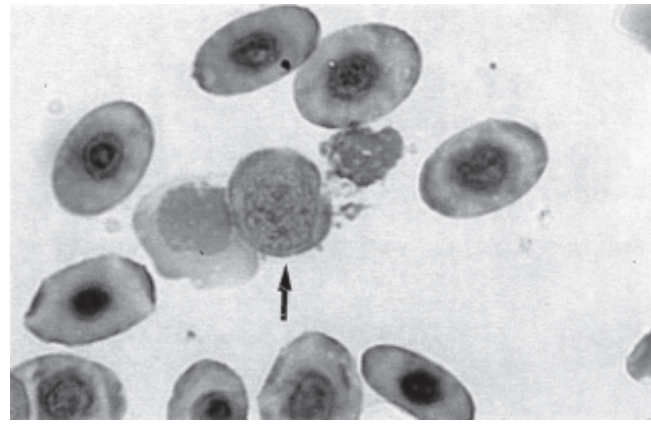

Figura 5-Fotomicrografia de aspirado de medula onde se observa um eritroblasto basófilo (seta). Núcleo grande com cromatina em grumos. Citoplasma com basofilia mais acentuada na periferia. Método de Rosenfeld. Aumento de 1450x

de cromatina condensada em grumos de aspecto grosseiro (Figura 8). Foram observadas também figuras de mitose entre as células diferenciadas (Figura 9).

Quanto à contagem total das células

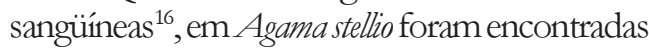
7 a $8 \times 10^{5} / \mathrm{mm}^{3}$ células eritrocíticas, em serpentes ${ }^{6} 0,57$ a $1,03 \times 10^{6} / \mathrm{mm}^{3}$, em Mabuya carinata $^{29}$ de 5 a $10 \times 10^{5} / \mathrm{mm}^{3}$, em Alligator mississipiensis ${ }^{10,12} 3,8$ e $4 \times 10^{5} / \mathrm{mm}^{3}$ e de 3 a 3,9 em Chelonia mydas ${ }^{11}$. Neste trabalho foram contadas $7,0 \times 10^{5}$ células eritrocíticas por $\mathrm{mm}^{3}$ de sangue; a disparidade com os dados encontrados por outros autores provavelmente deveu-se ao fato de se tratar de espécie e ambiente diferentes ou mesmo ao local do corpo do animal onde se fez a coleta do sangue.

No que diz respeito à análise

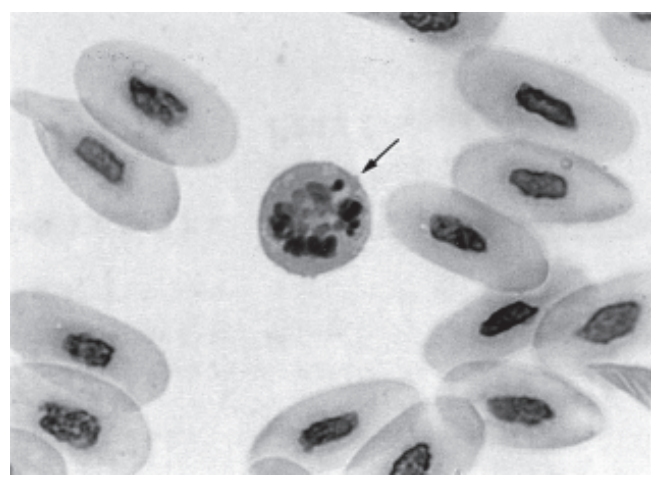

Figura 7 - Fotomicrografia de aspirado de medula evidenciando ao centro um eritroblasto (seta) em mitose. Núcleo em divisão, na fase de metáfase. Citoplasma basófilo de tonalidade cinza. Células maduras ao redor. Método de Rosenfeld. Aumento de 1450x 


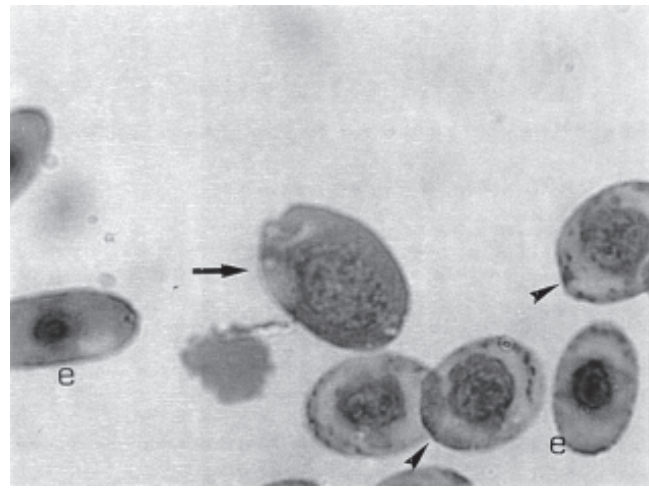

Figura 8 - Fotomicrografia de aspirado de medula apresentando ao centro um eritroblasto ortocromático (seta) elíptico, grande e de cromatina com grumos grosseiros. Ao redor, eritrócitos em maturação (cabeça de seta) e maduros (e). Método de Rosenfeld. Aumento de 1450x

morfológica de cortes histológicos de medula óssea, ocorrem ${ }^{30}$ "hemocitoblastos" aderidos ao endotélio dos sinusóides do fêmur de Gallus domestica e de Columbia livia ao lado de células mais diferenciadas de citoplasma mais basofílico que se dirigem ao centro do vaso, tais como eritroblastos basófilos, policromáticos e finalmente eritrócitos. Em Lacerta hispanica ${ }^{20}$ foram encontrados pro-eritroblastos e eritroblastos basófilo, policromático e ortocromático dentro dos vasos sinusóides, completando a série eritrocítica. Neste trabalho observaram-se sítios hematopoéticos na medula óssea femural do crocodiliano Caiman crocodilus yacare dentro dos vasos sinusóides que se distribuem por toda a medula óssea, principalmente na região mais central; foram vistas células da linhagem eritrocítica em várias fases de diferenciação, tendo sido vistas as mais imaturas aderidas ao endotélio, as intermediárias logo a seguir, e por fim os eritrócitos no centro da luz do sinusóide. Não foi possível identificar com precisão as fases de diferenciação a que as células pertenciam, pois nem sempre se apresentavam individualizadas, em preparados histológicos corados com HE. Nos cortes submetidos ao método de Gomori foi observada uma trama de fibras reticulínicas entre os sinusóides, coradas em preto. Estes dados coincidem com os já

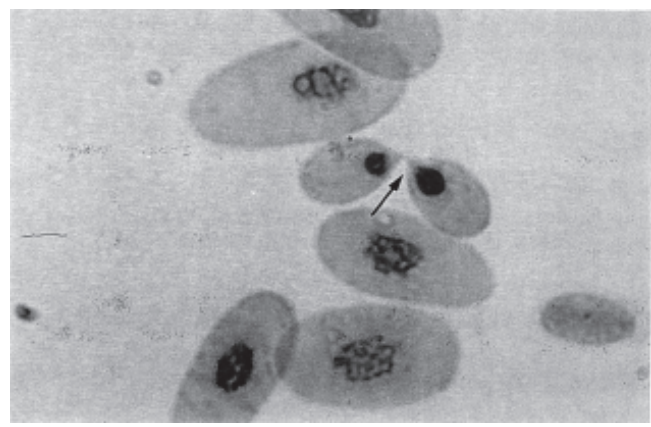

Figura 9-Fotomicrografia de esfregaço de sangue de Caiman crocodilus yacare onde se observa ao centro um eritrócito (seta) em fase final de divisão celular. Método de Leishman. Aumento de 1450x

referidos, uma vez que se trata de uma etapa evolutiva pela qual passou esta classe de vertebrados ${ }^{31} \mathrm{e}$ as espécies a ela pertencentes, bem como a das aves e parte da classe dos anfíbios. Todos esses vertebrados distinguemse dos mamíferos por terem eritropoese intravascular, enquanto estes últimos evoluíram a ponto de possuírem sítios da série vermelha no espaço extravascular ${ }^{30}$.

Com relação à análise morfológica de células do sangue periférico ${ }^{16}$, os eritrócitos de Agama stellio são de forma oval, corados ortocromaticamente, de núcleo oval, enquanto os eritroblastos policromáticos encontrados tanto na medula quanto no sangue circulante mostram-se pequenos e arredondados; os eritroblastos basófilos são arredondados, de citoplasma azul e de núcleo com estrutura reticular. Foram descritos ${ }^{32}$ hemocitoblastos com citoplasma basofílico e núcleo avermelhado; proeritroblasto com núcleo que ocupa quase toda a célula e citoplasma azul; eritroblasto basófilo com núcleo menor em relação às células das fases anteriores e de coloração mais intensa, com citoplasma basófilo; eritroblasto policromático de tamanho ainda menor e citoplasma alaranjado à medida que avança no processo de maturação. Relatam$\mathrm{se}^{17}$ células dessa linhagem na medula óssea de Lacerta muralis nas fases de proeritroblasto, eritroblastos I, II e III, proeritrócito e eritrócito. Em Emys orbicularis ${ }^{19}$, no processo de maturação as células passam 
pelas fases de eritroblasto basófilo e policromático, com núcleo proporcionalmente maior em relação às células maduras, com mitoses freqüentes. Em Caiman crocodilus yacar ${ }^{33}$, observaram-se eritrócitos de forma elíptica e núcleo elíptico condensado, com citoplasma de tonalidade róseo. Tal como em outras publicações ${ }^{17,32}$, nos preparados de aspirado de medula do trabalho agora realizado foram observadas células imaturas sem definição de linhagem de volume grande, núcleo eucromático e citoplasma acinzentado; próeritroblastos de núcleo eucromático contendo nucléolos, de forma arredondada, e citoplasma basófilo apresentando vacúolos; eritroblasto basófilo, de volume menor em relação à célula anterior, núcleo eucromático com nucléolos e citoplasma acinzentado; eritroblasto policromático, de volume ainda menor, núcleo eucromático podendo conter alguns nucléolos e citoplasma mais acinzentado mostrando vacúolos; eritroblasto, de forma arredondada, núcleo freqüentemente mitótico e citoplasma acinzentado; eritroblasto ortocromático, oval, de núcleo oval eucromático e citoplasma acinzentado; eritrócito, elíptico, de volume menor que o da fase anteriormente descrita, núcleo condensado em geral elíptico e citoplasma eosinofilico, róseo ou alaranjado.

\section{Conclusões}

1- A medula óssea femural, no terço distal, é um sítio hematopoético em exemplares jovens de Caiman crocodilus yacare.

2- Existem sítios da linhagem eritrocítica dentro dos capilares na região central do fêmur. As células menos diferenciadas encontraram-se aderidas à parede do sinusóide, enquanto as mais maduras se localizam mais ao centro do vaso. Há células imaturas no sangue circulante em processo de multiplicação.

3- Em esfregaços de aspirado de medula foram encontradas células imaturas eritrocíticas em diversas fases. Apresentaram forma arredondada nas fases imaturas, tornando-se elípticas com a maturação. Mostraram núcleo de cromatina frouxa nas fases imaturas e condensada nas maduras.

\section{Agradecimentos}

À Coordenadoria de Aperfeiçoamento de Pessoal de Ensino Superior (CAPES) pela concessão da Bolsa de Estudos (Doutorado) para o primeiro autor.

\section{Morphologic caracteristics of cells on the erytrocytic series of the Caiman crocodilus yacare (Daudin, 1802; Reptilia, crocodilia)}

\begin{abstract}
We studied hemopoietic cells in five young and healthy Brazilian cayman (Caiman crocodilus yacare). Peripheral blood samples (in EDTA) were collected by cervical venous sinuses puncture and bone marrow samples were obtained by femural bone needle aspiration. The bone marrow histological study was performed on femoral bone samples, with staining for HE, Giemsa and by Gomori technique for reticulin. Peripheral blood and marrow films were stained by Leishman or Rosenfeld technique. Active hemopoietic tissues were found by transversal section of the femur. Immature erythrocytic cells were found inside of sinusoid capilar vessels. The more immature erythrocytic cells were observed adhered to the vessel walls and the more mature ones were distributed through the central area. On marrow films, the erythrocytic immature cells showed a round shape with a fine nuclear chromatin pattern, while the mature cells were smaller, with an eliptic shape and a dense chromatin pattern.
\end{abstract}

Key-words:

Hemopoietic system. Erytrocyte. Erythrocytic series. Bone marrow. 


\section{Referências}

1 REESE, A. M. The blood of Alligator mississipiensis. Anatomy Record, v. 13, p. 37-44, 1917.

2 ZYLBERSZAC, S. Sur la nature des leucocytes réticulaires et spongieux du sang des reptiles. Canadian Review Séance Society Biology, v. 126, p. 97-98, 1937.

3 PIENAAR, U.d. V. Haematology of some south African reptiles. Johannesburg: Witwatersrand Univ. Press, 1962.

4 HELMY, F. M.; YAEGER, R. G.; HACK, M. H. Some histochemical observations on the blood cells of six species of turtles. Comparative Biochemistry and Physiology, v. 29, p. 1281-1283, 1969.

5 CAXTON-MARTINS, A. E. Cytochemistry of blood cells in peripheral smears of some West African reptiles. Journal of Anatomy, v. 124, n. 2, p. 393-400, 1977.

6 BOARD, P. G.; ROBERTS, J.; SHINE, R. Studies on the blood of australian elapid snakes - I. Morphology and composition. Comparative Biochemistry and Physiology, v. 56B, n. 4 , p. 353-356, 1977.

7 CAXTON-MARTINS, A. E.; NGANWUCHU, A. M. A cytochemical study of the blood of the rainbow lizard (Agama agama). Journal of Anatomy, v. 125, n. 3, p. 477-480, 1978.

8 DESSER, S. S. Morphological, cytochemical, and biochemical observations on the blood of the tuatara, Sphenodon punctatus. New Zelland Journal of Zoology, v. 5, p. 503-508, 1978.

9 DESSER, S. S.; WELLER, I. Ultrastructural observations on the erythrocytes and thrombocytes of the tuatara, Sphenodon punctatus (Gray). Tissue \& Cell, v. 11, n. 4, p. $717-726,1979$.

10 GLASSMAN, A. B.; BENNETT, C. E.; HAZEN, T. C. Peripheral blood components in Alligator mississippiensis. American Society for Transmission Microscopy, v. 100, p. 210-215, 1981.

11 WOOD, F. E.; EBANKS, G. K. Blood cytology and hematology of the green sea turtle, Chelonia mydas. Herpetologica, v. 40, p. 331-336, 1984.

12 MATEO, M. R.; ROBERTS, E. D.; ENRIGHT, F. M. Morphologic, cytochemical, and functional studies of peripheral blood cells of young healthy American alligators (Alligator mississippiensis). American Journal of Veterinary Research, v. 45, n. 5, p. 1046-1053, 1984.

13 ALLEMAN, A. R.; JACOBSON, E. R.; RASKIN, R. E. Morphologic and cytochemical caracteristics of blood cells from the desert tortoise (Gopherus agassizii). American Journal of Veterinary Research, v. 53, n. 9 p. $1645-1651,1992$.

14 CANNON, M. S. The morphology and cytochemistry of the blood leukocytes of Kemp's ridley sea turtle (Lepidochelys kempi). Canadian Journal of
Zoology, v. 70, p. 1336-1340, 1992.

15 ALLEMAN, A. R.; JACOBSON, E. R.; RASKIN, R. E. Morphologic, cytochemical staining, and ultrastructural characteristics of blood cells from eastern diamondback rattlesnakes (Crotalus adamanteus). American Journal of Veterinary Research, v. 60, n. 4, p. 507-514, 1999.

16 EFRATI, P.; NIR, E.; YAARI, A. Morphological and cytochemical observations on cells of the hemopoietic system of Agama stellio (Linnaeus). Israel Journal of Science, v. 6, n. 1, p. 23-31, 1970.

17 TAIB-CAZAL, E. Morphologie de l'érythropoiese chez Lacerta muralis (Laurenti). Acta Haematologica, v. 50, p. 56-63, 1973.

18 NANNO, R.; GERZELI, G.; POLVER, P. P. Tetrahydrofolate dehydrogenase in blood cells and in hematopoietic organs of different vertebrate species. Acta histochemistry, v. 63, p. 52-60, 1978.

19 VASSE, J.; BEAUPAIN, D. Erythropoiesis and haemoglobin ontogeny in the turtle Emys orbicularis L. Journal of Experimental Embryology and Morphology, v. 62, p. 129-138, 1981.

20 ZAPATA, A.; LECETA, J.; VILLENA, A. Reptilian bone marrow: an ultrastructural study in the Spasnish lizard, Lacerta hispanica. Journal of Morphology, v. 168, p. 137$149,1981$.

21 SHAH, R. V.; KINARIWALA, R. V.; RAMACHANDRAN, A. V. Changes in the visceral fat lipid metabolism, in relation to tail regeneration in the scincid lizard, Mabuya carinata: a histomorphological analysis. Anatomy Anz, v. 151, p. 137-143, 1982.

22 PATI, A.K.; THAPLIYAL, J. P. Erythropoietin, testosterone, and thyroxine in the erythropoietic response of the snake, Xenochrophis piscator. General Comparative Endocrinology, v. 53, n. 3, p. 370-374, 1984.

23 SPADACCI MORENA, D. D.; MORENA, P.; CIANCIARULLO, A. M.; BRUNNER JUNIOR, A Hemoglobin biosynthesis in bone marrow and peripheral blood erythroid cells of snake Waglerophis merremii (Reptilia, Ophidia, Colubridae). Memória do Instituto Butantan, v. 51, n.4, p. 133-139, 1989.

24 MOURA, W. L. Aspectos morfológicos e citoquímicos dos glóbulos sanguíneos e ultraestruturais de heterófilos, eosinófilos e trombócitos de Caiman crocodilus yacare (Daudin, 1802) (Reptilia, Crocodilia). 1996. Dissertação (Mestrado) - Escola Paulista de Medicina, São Paulo, 1996.

25 WIRTH, T. Hematologie comparé - contribution à l'étude des lignées medullaires chez les Reptiles: les lignées granulocytaires, lymphocytaires et monocytaires. Compte Rendue Academy Science, v. 274, n. 12, p. 1871-1873, 1972B. 
26 EL DEEB, S.; ZADA, S.; EL RIDI, R. Ontogeny of hemopoietic and lymphopoietic tissues in the lizard Chalcides ocellatus (Reptilia, Sauria, Scindidae). Journal of Morphology, v. 185, n. 2, p. 241-253, 1985.

27 PATI, A. K.; GUPTA, S. Circadian time dependence of erythropoietic and respiratory response of Indian garden lizard, Calotes versicolor, to mammalian urinary erythropoietin and thyroxine. General Comparative Endocrinology, v. 82, n. 3, p. 345-354, 1991.

28 FELDMAN, B. F.; ZINKL, J. G.; JAIN, N. C. Normal hematology of reptiles. In: SCHALM'S veterinary hematology. Philadelphia: Lippincott Williams \& Wikins, 2000B. p. 1126-1132.

29 SHAH, R. V.; KINARIWALA, R. V.; RAMACHANDRAN, A. V. Haematopoiesis and regeneration: changes in the cellular elements of blood and heemoglobin during tail regeneration in the scincid lizard, Mabuya carinata (Boulenger). Monitore zoologie italiani, v. 14, p. 137-150, 1980.

30 CAMPBELL, F. Fine structure of the bone marrow of the chiken and pigeon. Journal of Morphology, v. 123 , p. 405-440, 1967.

31 FELDMAN, B. F.; ZINKL, J. G.; JAIN, N. C. The hemopoietic system. In: SCHALM'S veterinary hematology. Philadelphia: Lippincott Williams \& Wikins, 2000A. p. 63-68.

32 WIRTH, T. Contribution à l'étude des lignées mèdullaires chez les Reptiles. Lignées erythrocitaire et plasmocitaire. Compte Rendue Academy Science Paris, v. 274 , n. 5 , p. $761-763,1972$ A.

33 MOURA, W. L.; OLIVEIRA, L. W.; MATUSHIMA, E. R.; EGAMI, M. I. Aspectos morfológicos e citoquímicos dos glóbulos sanguíneos de Caiman crocodilus yacare (Daudin, 1802) (Reptilia, Crocodilia).

Brazilian Journal of Veterinary Research and Animal Science, v. 36, n. 1, p. 45-50, 1999. 